\title{
Avaliação de Satisfação e de Percepção de Qualidade em Intervenção Pública Realizada em um Aglomerado Subnormal por meio do Programa de Aceleração do Crescimento (PAC)
}

\section{An Assessment of Satisfaction and Quality Perception with a Public Intervention at a underprivileged community under the Programa de Aceleração do Crescimento (PAC)}

Guido Vaz Silva

Doutorado em Engenharia de Produção pela Universidade Federal do Rio de Janeiro, Professor da Universidade Federal Fluminense, Brasil, guido_vaz@hotmail.com

http://lattes.cnpq.br/9847110744718539

Resumo: O Programa de Aceleração do Crescimento do governo federal brasileiro (PAC) possibilitou que diversas intervenções urbanas entre 2008 e 2012 fossem realizadas por meio de diversos entes públicos das esferas federal, estadual e municipal. Analisa-se a satisfação e a percepção de qualidade de cidadãos de uma intervenção urbana realizada no aglomerado subnormal Nova Esperança, Macaé, Rio de Janeiro, RJ, Brasil, utilizando uma abordagem multimetodológica potencializada por um processo de triangulação entre quatro métodos. No referencial teórico, o artigo problematiza os processos de urbanização e favelização historicamente estabelecidos no Brasil desde a segunda metade do século XX e discute aspectos da gestão de desempenho em governos, com ênfase à avaliação de satisfação sobre serviços públicos. No estudo de caso conclui-se que houve serviços que melhoraram, porém outros não. Por fim, discute-se o contraste encontrado entre a avaliação geral e a avaliação serviço a serviço no caso Nova Esperança, apontando-se implicações para a pesquisa e para a prática.

Palavras-chave: governos locais, avaliação de satisfação, qualidade de serviços públicos, serviços públicos urbanos.

Abstract: The Program of Acceleration and Growth (PAC) of the federal government of Brazil made possible that several urban interventions between 2008 and 2012 were performed through federal, state and municipal public entities. We analyze the perception of beneficiaries on satisfaction, with an urban intervention, at the underprivileged community of Nova Esperança, Macaé, Rio de Janeiro, RJ, Brazil, using a multi methodological approach enhanced by a triangulation process between four methods. The theoretical framework discusses the processes of urbanization and formation of slums in Brazil ever since the second half of the twentieth century and discusses aspects of management performance with emphasis on evaluation of satisfaction with public services. The case study concluded that some services have improved, but others did not. Finally, we discuss the contrast between the overall evaluation and the assessment of each service at Nova Esperança, suggesting implications for research and practice.

Keywords: local government, assessment of satisfaction, quality of public services, urban public services

Texto completo em português: http://www.apgs.ufv.br Full text in Portuguese: http://www.apgs.ufv.br

Introdução

O Programa de Aceleração do Crescimento (PAC) é considerado um dos pilares dos governos petistas recentes - governo Lula (20072010) com o PAC 1 e governo Dilma Rousseff (2011-2014) com o $P A C$ 2. Em termos de volume financeiro aportado, o PAC 1 realizou investimentos de $\mathrm{R} \$ 619$ bilhões. O PAC era composto por três eixos principais: infraestrutura logística, infraestrutura energética e infraestrutura social e urbana (Ministério da Fazenda, 2013). Esse terceiro eixo destinava parte dos recursos para a seleção de zonas urbanas classificadas como Zonas Especiais de Interesse Social (ZEIS).

Apesar do PAC continuar sendo uma das principais apostas como propulsor da economia nacional, haja vista a continuidade com o PAC 2, percebe-se carência de estudos que discutam os impactos do programa (Leitão, 2009; Oliveira, 2011).

Este estudo realiza uma análise da percepção dos cidadãos residentes de uma intervenção urbana realizada entre 2008 e 2012 no âmbito do Programa de Aceleração do Crescimento. Tal intervenção aconteceu no aglomerado subnormal Nova Esperança no município de Macaé, estado do Rio de Janeiro. Segundo o IBGE (2011), aglomerado subnormal é o conjunto constituído por 51 ou mais unidades habitacionais caracterizadas por inexistência de título de propriedade e pelo menos uma das características a seguir: (i) irregularidade das vias de circulação e do tamanho e forma dos lotes; e/ou (ii) carência de serviços públicos essenciais (como coleta de lixo, rede de esgoto, rede de água, energia elétrica e iluminação pública). $\mathrm{O}$ artigo utiliza uma abordagem multimetodológica potencializada por um processo de triangulação para analisar a satisfação da população residente com a intervenção urbana em questão.

Macaé é um dos principais pontos de exploração de petróleo no país, o que lhe confere uma dinâmica econômica muito pujante

Correspondência/Correspondence: Universidade Federal Fluminense, Centro Tecnológico, Escola de Engenharia. Rua Recife, s/n. Jardim Bela Vista. 28895532 Rio das Ostras, RJ - Brasil guido_vaz@hotmail.com 
desde meados da década de 70 . O crescimento da indústria do petróleo provocou também o aumento populacional, com a chegada de pessoas de diversas partes do país e do mundo para trabalhar em Macaé, quadriplicando o número de habitantes em apenas quatro décadas, conforme Tabela .

Tabela 1 - Evolução da população de Macaé

\begin{tabular}{|c|c|}
\hline Ano & Total de habitantes \\
\hline 1950 & 45.720 \\
\hline 1960 & 58.254 \\
\hline 1970 & 65.318 \\
\hline 1980 & 75.863 \\
\hline 1991 & 100.895 \\
\hline 2000 & 132.461 \\
\hline 2010 & 206.728 \\
\hline
\end{tabular}

Nota. Fonte: dados dos censos demográficos do IBGE de 1950 a 2010, Anuário Macaé 2012 (Macaé, 2012).

Concomitantemente, a força econômica da indústria petrolífera fez com que Macaé estivesse presente entre os cem municípios do país em classificações econômicas que se baseiam no Produto Interno Bruto (PIB), desde que a série histórica começou a ser divulgada pelo IBGE no ano 2000. Segundo dados do IBGE (2016), em valores correntes dos anos de medição, Macaé chegou a ter, em 2002, o 18ํ PIB municipal brasileiro, com $R \$ 9.280 .540 .000,00$ e o $12^{\circ}$ lugar em termos de PIB per capita, com $\mathrm{R} \$ 64.519,00$. Em relação a 2011, último ano de divulgação pelo IBGE, o município caiu nos dois ranqueamentos, mas ainda aparece com o $42^{\circ}$ melhor PIB municipal, $R \$ 12.558 .285 .000,00$, e com o 82ํㅡ PIB per capita, $R \$ 59.116,45$. Tais fatos possibilitam ainda aumentos significativos dos recursos orçamentários municipais devido ao crescimento histórico de arrecadações provenientes dos royalties pagos pela indústria e de impostos municipais, principalmente, pelo imposto sobre a prestação de serviços de qualquer natureza (ISS). Por exemplo, os royalties recebidos em 1999 somavam $R \$$ 34.757.683,06, enquanto em 2009 foram de $R \$ 367.797 .120,71$, em valores correntes (Macaé, 2016).

Em franco contraste, no que tange o desenvolvimento humano municipal, na última análise realizada pelo PNUD (2013) sobre o índice de desenvolvimento humano dos munícipios brasileiros com referência ao Censo de 2010, Macaé está posicionado entre a $304^{\mathrm{a}}$ e 319a posição (empatado com 16 municípios) dentre os 5.507 municípios investigados, com um índice de 0,764. Isto o classifica como um município de desenvolvimento médio. A Tabela 2 demonstra certa evolução entre as três medições decenais realizadas, mas, em termos de posicionamento relativo aos outros entes municipais, Macaé ainda se distancia dos cem melhores. Isso porque, em 1991, Macaé encontrava-se entre a 385a e 379a posição, com o índice de 0,534 , e, no ano 2000, entre a 408 e 425a posição, com a medição de 0,665.

Tabela 2- Evolução do IDH-M macaense

\begin{tabular}{|c|c|c|c|c|c|}
\hline Ano & $\begin{array}{c}\text { Dimensão } \\
\text { Educação }\end{array}$ & $\begin{array}{c}\text { Dimensão } \\
\text { Longevidade }\end{array}$ & $\begin{array}{c}\text { Dimensão } \\
\text { Renda }\end{array}$ & IDH-M & Evolução \\
\hline 1991 & 0,337 & 0,663 & 0,683 & 0,534 & - \\
\hline 2000 & 0,531 & 0,751 & 0,737 & 0,665 & $24,53 \%$ \\
\hline 2010 & 0,681 & 0,828 & 0,792 & 0,764 & $14,89 \%$ \\
\hline
\end{tabular}

Nota. Fonte: Adaptado dos dados disponibilizados por PNUD (2013).

Ademais, este município apresentou um crescimento significativo na quantidade de domicílios presentes em aglomerados subnormais. Segundo o censo de 2000 (IBGE, 2001), Macaé possuía 5.886 domicílios nessas condições. Por sua vez, a medição realizada pelo censo de 2010 (IBGE, 2011) apresentou um crescimento de 94\% no número de domicílios nas mesmas condições, correspondente a 11.413 domicílios.

Dessa forma, considera-se que o município de Macaé possui características socioeconômicas que o tornam interessante objeto de análise, visto que, com o aumento expressivo da presença de agentes produtivos da cadeia do petróleo e gás em seus domínios, vivenciou-se intenso aumento da atividade econômica com reflexos no PIB e PIB per capita, indicadores que têm capacidade para demonstrar o nível de produção. Por outro lado, utilizando o mesmo período entre os censos de 2000 e 2010 (IBGE, 2001; IBGE, 2011), os números de indicadores que utilizam perspectivas além da econômica, tais como o IDH-M (educação, longevidade e renda) e a quantidade de domicílios presentes em aglomerados subnormais (precarização de serviços públicos e condições de habitação) demonstram que tais recursos públicos (aumento dos recursos orçamentários provenientes de royalties e impostos municipais privados oriundos da pujante atividade econômica local) não foram capazes de impactar condições sociais e relacionadas à qualidade de vida de boa parte dos cidadãos residentes.

A partir do entendimento da importância de que ações e serviços públicos em ambientes urbanos degradados entreguem mais qualidade gerando mais satisfação nas populações alvos, a questão dessa pesquisa se apresenta da seguinte forma: qual foi o nível de 
satisfação da população alvo de uma intervenção urbana do PAC em um aglomerado subnormal em relação à qualidade da infraestrutura e sua relação com a prestação de serviços públicos locais após a intervenção vis-à-vis a situação anterior à intervenção?

Procedeu-se uma investigação, então, com o objetivo de analisar o nível de satisfação de cidadãos residentes em relação às mudanças produzidas pela entrega de novos sistemas de infraestrutura urbana (unidades habitacionais, implantação de um sistema de distribuição de água, de um sistema de coleta de esgoto e de um sistema de drenagem de águas pluviais) e sobre a percepção de qualidade com serviços urbanos básicos (serviços de educação e serviços de saúde). Com isso, objetiva-se gerar insumos importantes para reflexões acerca do projeto e prestação de serviços urbanos.

$\mathrm{Na}$ segunda seção, descreve-se o método e os procedimentos de pesquisa adotados neste estudo. $\mathrm{Na}$ terceira seção, o artigo problematiza os processos de urbanização e favelização historicamente estabelecidos no Brasil desde a segunda metade do século $\mathrm{XX}$. Aborda-se o estado da literatura em relação à gestão de desempenho na gestão pública, com especial atenção a conceitos centrais do tema e sobre a relação entre a avaliação de satisfação de cidadãos e a prestação de serviços públicos locais. Na quarta seção, apresenta-se o estudo de caso, introduzindo a realidade préintervenção do aglomerado subnormal Nova Esperança e, em seguida, discutindo detalhadamente a percepção de satisfação dos cidadãos residentes com cada um dos oito serviços urbanos analisados. Os serviços urbanos analisados foram escolhidos por serem serviços de competência municipal. Por fim, discute-se o contraste encontrado entre a avaliação geral e a avaliação serviço a serviço no caso Nova Esperança, apontando-se implicações para a pesquisa e para a prática de intervenções em aglomerados subnormais que objetivem produzir mais satisfação em relação à qualidade dos serviços.

\section{Procedimentos Metodológicos}

Este artigo se beneficia de uma abordagem multimetodológica mixed methods - (Johnson, Onwuegbuzie \& Turner, 2007), seguida de um processo de triangulação (Moran-Ellis et al., 2006) entre quatro métodos:

(i) Quinze entrevistas em profundidade, individuais, de viés eminentemente qualitativo, com foco em descrição e explicação. $O$ número da amostra se justifica pelo critério de saturação, ou seja, quando se interrompe a coleta de dados ao se constatar que os elementos para subsidiar a teorização ou discussão almejadas estão se repetindo e não são mais depreendidos a partir do campo de observação (Fontanella et al., 2011). Destas, seis foram realizadas com engenheiros, arquitetos e assistentes sociais que compuseram a equipe técnica municipal responsável pela condução e projetação das intervenções. Nove foram realizadas com cidadãos que residiam no local tanto antes, quanto depois da intervenção. Foi definido que os moradores deveriam ter um perfil de lideranças espontâneas, ou seja, não deveriam ter cargos formais de representatividade na comunidade e precisavam ter participado com certa constância e relevância durante o processo de intervenção na comunidade. $O$ autor solicitou, ainda, que fossem incluídos cidadãos reativos ao processo.

(ii) Realização de um levantamento survey quantitativo, com a aplicação de um questionário estruturado em uma amostra estatisticamente representativa da população residente que recebeu as intervenções. A quantidade de 63 respondentes foi obtida por meio de um processo de amostragem para amostras sem reposição e de população finita (Spiegel, 2009). Para operacionalização da equação de amostragem proposta por Spiegel (2009), utilizou-se como parâmetros: um universo de 800 domicílios, quantidade de residências da área que recebeu a intervenção; intervalo de confiança de $90 \%$, representado na curva normal pelo valor de 1,65 ; aceitou-se um erro amostral de 10\%; e, por não terem sido identificados estudos anteriores com o mesmo formato e com a mesmo universo, utilizou-se o valor de $50 \%$ para a variável proporção. $\mathrm{O}$ autor aplicou o questionário pessoalmente pelas ruas do aglomerado subnormal em análise, garantindo que todas as ruas tivessem ao menos um domicílio coberto por um respondente adulto.

(iii) Observações diretas na realidade pesquisada através de visitas in loco, não-guiadas por moradores, por parte do pesquisador, para suscitar percepções idiossincráticas e potencialmente libertas do viés que algum morador poderia embutir no processo de observação.

(iv) A análise documental de material oficial sobre as intervenções realizadas, elaborado em âmbito municipal e federal. Principalmente, o Plano Plurianual de Macaé (2010/2013), o Plano Local de Habitação de Interesse Social de Macaé, Relatórios do PAC Nova Esperança, Matriz de Indicadores para pós-ocupação do Ministério das Cidades e o Caderno de Orientação Técnico Social (COTS).

Para guiar a conduta do pesquisador no campo, foi construído um protocolo de pesquisa. O protocolo de pesquisa é um instrumento que contém os procedimentos e as regras gerais que devem ser seguidos em um estudo de caso, ou seja, trata-se de um instrumento fundamental e necessário na condução de estudo de casos (Yin, 2009; Miguel \& Sousa, 2012). O objetivo principal das entrevistas com os engenheiros, arquitetos e assistentes sociais foi conhecer suas perspectivas sobre o processo das intervenções, desde a escolha do aglomerado subnormal, alvo da ação urbanística, até a implantação dos serviços públicos no local. Por sua vez, as entrevistas de profundidade e o levantamento survey realizados com os moradores tiveram como foco a coleta de elementos perceptivos que comparassem o desempenho de um conjunto de serviços antes e depois da intervenção, desenvolvendo, 
dessa forma, o entendimento sobre o grau de satisfação e de percepção de qualidade desses cidadãos com tais serviços, bem como a indicação de evidências que suportassem essas percepções.

Para o tratamento dos dados coletados por meio do survey, os 63 questionários respondidos foram tabulados e possibilitaram análises estatísticas para caracterizar o grau de satisfação da comunidade residente com a intervenção realizada e os serviços públicos locais. Cabe salientar que a delimitação da pesquisa optou por não coletar as percepções dos moradores em relação às novas unidades habitacionais entregues pela intervenção, haja vista que nem todos os respondentes, tanto nas entrevistas, quanto no survey, foram contemplados com uma nova unidade habitacional para residir. Ademais, a realização do survey possibilitou lançar mão de uma análise quantitativa para fins de comparação com os resultados qualitativos obtidos por meio das entrevistas, visitas in loco e análise documental.

Para o tratamento dos dados coletados nas entrevistas de profundidade, tanto as realizadas com a equipe técnica quanto as com os moradores, foi utilizado o método de análise de conteúdo. Para Bardin (2008), a análise de conteúdo compreende um conjunto de técnicas de análise das comunicações visando obter, por procedimentos sistemáticos e objetivos de descrição do conteúdo das mensagens, indicadores (quantitativos ou não) que permitam a inferência de conhecimentos relativos às condições de produção/recepção (variáveis inferidas) destas mensagens.

Esse processo envolveu três etapas: (1) transcrição integral do material bruto; (2) tratamento de dados coletados nas entrevistas de profundidade, utilizando o método da análise de conteúdo; (3) categorização dos dados tratados e síntese de resultados. Para fins de organização e operacionalização do método, esta pesquisa utilizou o software atlas.ti para transcrição, tratamento, categorização e síntese do material bruto coletado nas entrevistas de profundidade.

Para transcrição do material bruto, foi realizada a transposição ipsis litteris do que foi dito, considerando pausas, interjeições e eventuais erros morfossintáticos para ilustrar e reforçar os conteúdos coletados. Dessa forma, tais trechos utilizados neste artigo (em aspas e itálico) podem apresentar menos rigor gramatical, já que advém da linguagem coloquial dos entrevistados.

Sobre a categorização de um texto, Bardin (2008) defende o desmembramento do texto em unidades (categorias), segundo agrupamentos lógicos. Este processo estrutura os elementos discursivos de maneira taxonômica (Bailey, 1994), segundo a lógica de estruturação interna do conteúdo levantado e os objetivos da investigação científica de acordo com o inventário de suas semelhanças e diferenças. A principal contribuição dessa técnica reside em proporcionar camadas sintéticas dos conteúdos coletados nas 15 entrevistas em profundidade.

\section{Fundamentos Teóricos}

Processos de urbanização e favelização

A forma pela qual o processo de migração da população rural para as cidades brasileiras ocorreu e sua disposição espacial nos centros urbanos retratam desigualdades socioterritoriais. Os efeitos sobre as cidades costumam ser a divisão evidente entre espaços desenvolvidos, legais e com infraestrutura adequada (ditos formais) e espaços carentes, precários, ilegais e com problemas relacionados à qualidade de vida com seus desdobramentos pelos diversos setores: saneamento básico, habitação, transportes, lazer, educação, saúde, dentre outros (ditos informais) (Telles, 2010).

Para Brito e Pinho (2012), o processo de urbanização no Brasil ocorreu mais rápido que nos países desenvolvidos. Apenas nos anos 70 a população urbana ultrapassou a rural, fazendo com que a população urbana, em apenas meio século, aumentasse 7,3 vezes. A taxa de crescimento declinou entre os anos 2000-2010, vinculada à diminuição da taxa de fecundidade e do ritmo de migração ruralurbana.

Sob outra ótica, Lago e Ribeiro (2001) defendem que os movimentos de (di)visão nas cidades, demostrados pela cada vez maior divisão entre bairros e favelas, ocorrem a partir da compreensão da cidade como objetivação do espaço social entre os atores sociais. Os autores, ainda, explicam que é possível identificar duas concepções distintas sobre os conceitos de espaço e de distância sociais: uma psicossocial, que entende a distância social como o resultado de preferências relacionais de certos grupos em relação a outros, e outra sociológica, na qual o distanciamento espacial resulta de relações de proximidade e separação que são, antes de tudo, relações hierárquicas produzidas pela distribuição desigual dos capitais econômico, social e simbólico, que conformam as relações de dominação na sociedade entre as classes sociais. (Lago \& Ribeiro, 2001).

Analisando o processo na cidade do Rio de Janeiro, Lago e Ribeiro (2001) ainda estudam como as favelas nos anos 90 se desenvolveram. Eles argumentam que a causa da migração contínua e acentuada, principalmente do Nordeste para o Sudeste, explica cada vez menos o crescimento demográfico nas favelas a partir da década de 90. A inferência realizada em cima de dados censitários apontou que o surgimento e a expansão de favelas ocorridos naquele momento (principalmente as novas favelas da zona oeste carioca) eram melhor explicados por meio da mobilidade espacial no interior do próprio município, seja do bairro para a favela ou de favelas consolidadas para favelas recentes.

Historicamente no Brasil, o Estado se distanciou com a ausência de intervenções públicas de contenção ou reversão desses espaços carentes, precários, ilegais e com problemas relacionados à qualidade de vida. Esse distanciamento sofreu inflexão a partir de meados dos anos 90 em diversas cidades brasileiras, com destaque 
para os programas como o Favela Bairro, no Rio de Janeiro, e o Cingapura, em São Paulo. Para Maricato (2009), os investimentos em habitação e saneamento foram retomados com mais intensidade apenas a partir de 2007, com o PAC, ainda que Leitão (2009) o considere aquém do necessário, diante do passivo de aglomerados subnormais existentes.

Abiko e Coelho (2009) coadunam que a frequência de atuação em melhorias habitacionais e urbanísticas de assentamentos urbanos degradados aumentou a partir dos anos 2000. Todavia, pontuam que certas urbanizações de favelas objetivam apenas causar melhorias superficiais ("embelezamento") nas áreas urbanas, eliminar situações de irregularidade fundiária e promover a valorização imobiliária do entorno. Comentam também que existem ações mais profundas ocorrendo no país que visam melhorar os níveis de vida da população por meio da diminuição dos impactos ambientais, insegurança geológica, precariedade nas condições de saneamento e falta de acesso a serviços urbanos (Abiko \& Coelho, 2009).

É possível diferenciar as características de favelas (Muxica, 2011). Nesse sentido, ainda conforme Abiko e Coelho (2009), são variáveis: o tamanho do assentamento e sua localização à cidade; aspectos de interação local; graus de adensamento; graus de consolidação, ou seja, habitações edificadas com materiais permanentes e com acabamento; nível de precariedade no que se refere à condição das edificações, dos riscos de desabamentos e inundações, e da presença e qualidade tanto de infraestrutura como dos serviços urbanos; percentual de ocupantes que são locatários; e situação socioeconômica dos residentes. Sob essa perspectiva, então, é possível o estabelecimento de gradações entre áreas degradadas. Conforme já dito, esta pesquisa delimitou como objeto um aglomerado subnormal de Macaé.

Estabelece-se, ainda, posição sobre a real necessidade de ações diretas ou de governança do poder público sobre problemas sociais dessa natureza. Portanto, a discussão sobre o desempenho da ação governamental urge para essas realidades, sobre as quais se voltam as análises presentes neste artigo.

\section{Gestão do Desempenho de Serviços Públicos: Satisfação e Qualidade do Serviço}

Segundo Boyne, Meier e Walker (2006), o tema gestão de desempenho, elemento-chave das reformas do setor público desde 1980, torna-se necessário para a etapa de avaliação de qualquer ação pública. O foco na medição de desempenho faz parte da abordagem mais ampla das ondas da New Public Management (NPM) que abrangeu boa parte das principais economias dos Estados do ocidente (Andrews, Boyne, Law \& Walker, 2005).

Bouckaert e Van Dooren (2009) acrescentam que, desde a nova emergência da discussão no âmbito da NPM, as principais medições focavam o entendimento entre os recursos (inputs) e a eficiência e que, a partir de meados dos anos 90, o foco mudou para indicadores que demonstrem a qualidade dos serviços, da vida dos cidadãos e a da governança pública.

Sano e Filho (2013) coadunam com essa visão defendendo ser crucial que as ações governamentais continuem buscando mais desempenho em termos de eficiência, eficácia e efetividade (3Es). Contudo, eles ressaltam que a multifacetada literatura existente sobre o tema contribui para que persistam a falta de clareza sobre o foco de análise e metodologias, por vezes conflitante, que acabam não auxiliando o gestor público e a sociedade em geral no momento de avaliação de ações governamentais.

Sobre isso, Bouckaert e Van Dooren (2009) apresentam o modelo input-output, na Figura 1, para a compreensão dos diversos aspectos que podem ser avaliados em uma política ou serviço público.

Figura 1. Ciclos de Elaboração e Gestão de Políticas e Serviços Públicos.

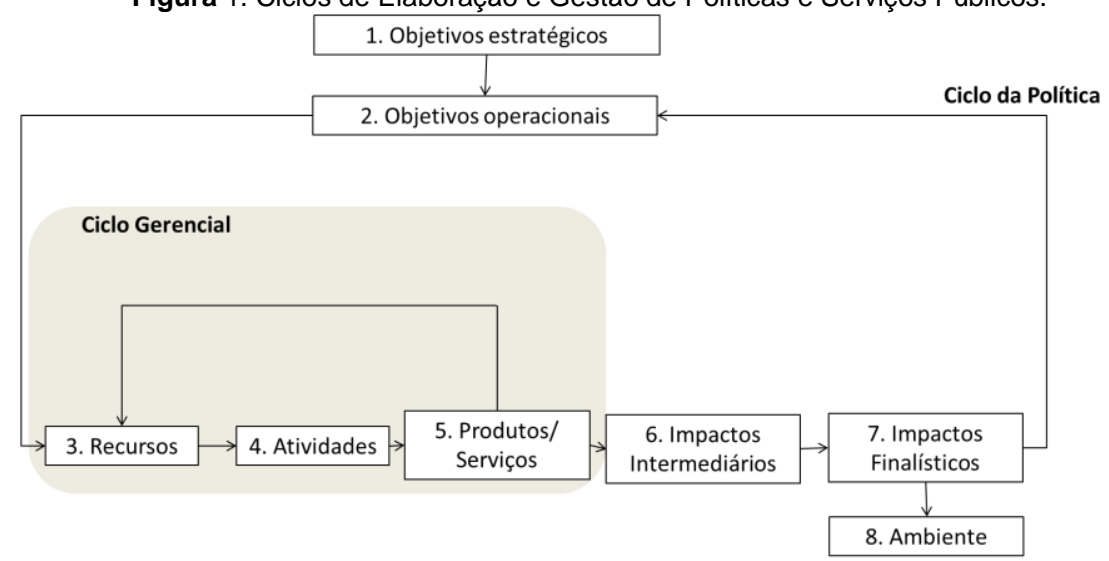

Fonte: Bouckaert e Van Dooren (2009)

De forma análoga, Ball e Beckett (1991), a partir de análises realizadas em governos locais ingleses, apresentam possíveis diferentes tipos de indicadores de desempenho sobre elementos de um serviço público. No primeiro tipo estão os indicadores baseados 
em recursos (inputs), que estão centrados na mensuração da utilização de recursos (indicadores de economicidade, indicadores de eficiência, indicadores de custo-benefício). No segundo tipo, estão indicadores de eficácia operacional, que medem o atingimento de objetivos planejados para a ação. No terceiro tipo estão indicadores sobre as unidades produzidas de produtos ou serviços (outputs), que avaliam os níveis de prestação de serviços, normalmente por meio do efeito do serviço em clientes (exemplo: qualidade percebida), sem realmente medir as mudanças de bemestar produzidas. E, por fim, o quarto tipo reúne indicadores de efetividade que buscam medir a melhora no bem-estar do indivíduo alvo, ou seja, os impactos (outcomes) provocados pela ação.

A partir da Figura 1 e de diversos autores (Bouckaert \& Van Dooren, 2009, Heinrich, 2010, Sano e Filho, 2013), este artigo assume como definições para os 3 Es: (i) eficiência como a relação entre os recursos (inputs) e os produtos e serviços (outputs); (ii) eficácia como a medida que avalia o alcance dos objetivos e do nível das entregas, ou seja, foca nos produtos ou serviços (outputs); (iii) efetividade como o nível de impactos positivos ou negativos (outcomes) proporcionados pela ação em análise.

Especificamente sobre análises das percepções de cidadãos sobre os produtos ou serviços entregues por governos (avaliação de cidadãos sobre os outputs), há autores (Altman, 2001, Scott \& Vitartas, 2008, Van Ryzin, 2004) que tentaram acessar o nível de satisfação de cidadãos por meio de levantamentos survey e de entrevistas em profundidade.

Sobre isso, Cardoso e Cardoso (2011) desenvolveram um instrumento de pesquisa a partir do modelo European Costumer Satisfaction Index (ECSI), adicionando itens dos modelos SERVQUAL, Common Measurement Tool (CMT) e Common Assessment Framework (CAF), e buscaram entender o que conformava a satisfação de munícipes portugueses em relação aos serviços prestados a eles. Para tal eles investigaram a relação entre certos antecedentes (imagem, expectativas, valor percebido e, com destaque particular para a qualidade percebida) e consequentes níveis de satisfação, a partir dos elementos lealdade e reclamações. A investigação objetivava esclarecer melhor as variáveis que afetam a satisfação de cidadãos que recebem serviços públicos locais, questão bastante explorada e analisada sobre o comportamento de consumidores pelas organizações privadas, haja vista os modelos que os autores utilizaram como partida. Os resultados confirmaram a correlação entre essas variáveis, com destaque para o constructo qualidade percebida, que demostrou correlação positiva em todos os seus aspetos analisados (competência/atendimento; credibilidade; tangibilidade/segurança; acessibilidade) em relação à satisfação global (Cardoso \& Cardoso, 2011).

É nesse sentido que, mesmo entendendo que existem outras variáveis que contribuem para explicar, em partes, níveis de satisfação ou insatisfação de uma determinada população em relação à certa ação executada pelo poder público, este artigo procurou aprofundar a percepção de qualidade dos serviços prestados e a sua influência nos níveis de satisfação dos cidadãos residentes.

\section{Discussão}

Estudo de Caso: Aglomerado subnormal objeto da análise: Intervenções em Nova Esperança

O município de Macaé participou em 2007 do processo seletivo federal com 19 propostas conceituais para receber financiamento do Programa de Aceleração do Crescimento (PAC), como uma tentativa de melhoria das condições precárias de infraestrutura urbana de alguns de seus aglomerados subnormais. Essas propostas foram embasadas pelo Plano Local de Habitação de Interesse Social (PLHIS) (Figura 2). Para o PLHIS de Macaé (Macaé, 2010), são considerados aglomerados subnormais tanto as ocupações espontâneas e originalmente desprovidas de qualquer infraestrutura ou planejamento, quanto assentamentos implantados com algum nível de organização, ainda que pequenos, provenientes de loteamentos irregulares.

Figura 2- ZEISs, SRUs e SPA (apenas a llha Leocádia em verde) de Macaé.

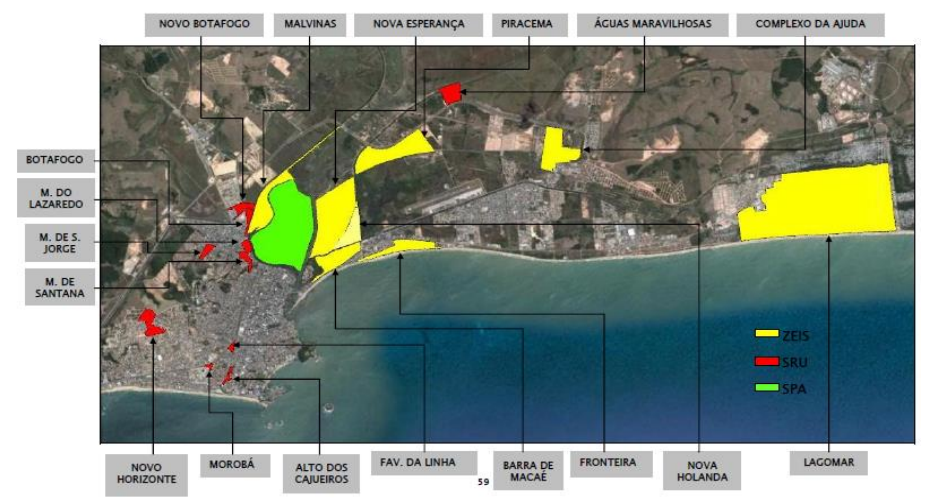

Fonte: PLHIS Macaé (Macaé, 2010). 
A única proposta aprovada pelo governo federal, das 19 submetidas por Macaé, foi a intervenção no aglomerado subnormal Nova Esperança (Figura 2 e ampliado na Figura 3), estudado nesse artigo. Tratou-se de um aporte de $\mathrm{R} \$ 10.400 .000,00$ (dez milhões e quatrocentos mil reais) somados a uma contrapartida municipal de $R \$ 4.000 .000,00$ (quatro milhões de reais), para serem empregados nesse aglomerado subnormal. Trata-se de um projeto de intervenção finalizado, ou seja, seu ciclo de elaboração e entrega foi completado.

Figura 3 - Perspectiva da localidade de Nova Esperança e Nova Holanda no bairro de Barra de Macaé, com ênfase na área em vermelho do terço urbanizado pela intervenção objeto de análise.

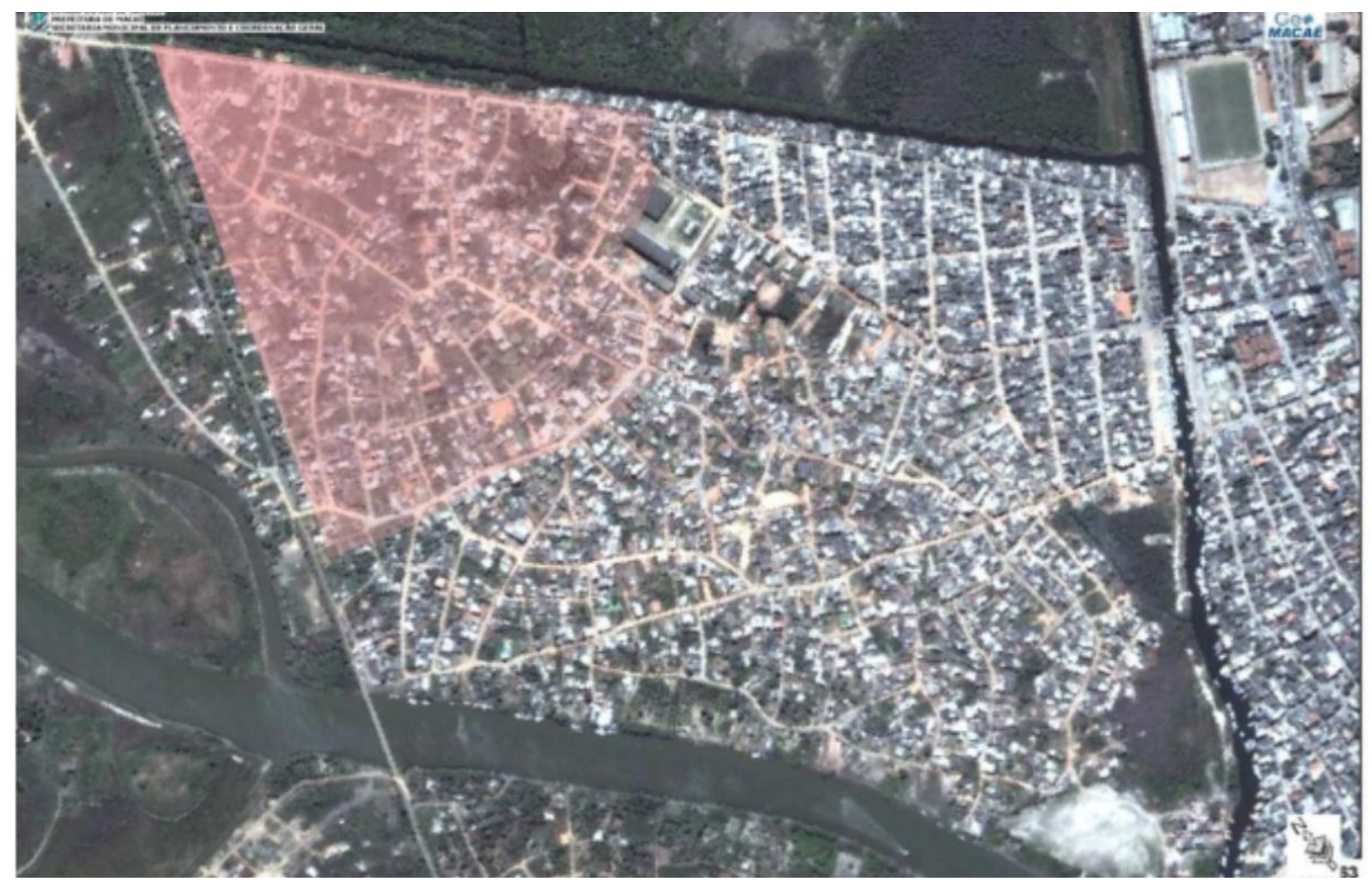

Fonte: Plano Local de Habitação de Macaé (Macaé, 2010).

Ainda segundo o PLHIS (Macaé, 2010), antes da intervenção, os serviços públicos locais eram precários. A comunidade local não possuía um sistema viário pavimentado e organizado, com ruas identificadas, dificultando a circulação interna, inclusive, de veículos oficiais. A rede de abastecimento de água não existia, bem como não havia nenhum sistema de esgotamento sanitário. Como prática comum, a população cavava o chão em busca de água e a utilizava na situação em que era encontrada, configurando um significativo risco de insalubridade. Havia espaços com iluminação insuficiente e muitas ligações clandestinas.

A estrutura das habitações era precária e muitas vezes insalubre, com espaços mínimos e de segurança insuficiente. Diversas habitações encontravam-se em áreas consideradas de risco (áreas de risco em Nova Esperança foram consideradas as faixas marginais de corpo hídrico, de linha férrea, áreas de rede de alta tensão ocupadas ou classificadas em vulnerabilidade social grave) (Macaé, 2010).

Com os recursos aprovados pelo governo federal no âmbito do
PAC, os técnicos da equipe interna da prefeitura começaram a elaborar o projeto da intervenção. Todavia, não foi possível contemplar toda a comunidade diante da extensão territorial de Nova Esperança. Com essa restrição de recursos, como um dos piores problemas do bairro era o de drenagem pluvial e consequentes inundações, a equipe técnica da intervenção dividiu o bairro em três bacias hidrográficas. A partir desse estudo, decidiu-se utilizar os recursos apenas no terço mais crítico da comunidade sob esse aspecto, em vermelho, na Figura 3. Parte essa que possuía em torno de 800 domicílios, segundo dados do IBGE (2016) sobre os três setores censitários que representam a parte urbanizada: 330240305010051,330240305010052 e 330240305010045.

\section{Análise de Dados}

Nesta seção do artigo são apresentados os dados coletados. Tais dados buscaram captar as percepções de qualidade com os serviços públicos locais em relação à condição pré-intervenção. 
Tabela 3 - Percentuais de avaliação dos serviços pelos cidadãos

\begin{tabular}{|c|c|c|c|c|c|c|c|c|c|c|c|c|c|c|}
\hline \multirow{3}{*}{ Serviço } & \multicolumn{14}{|c|}{ Respostas Válidas } \\
\hline & \multicolumn{2}{|c|}{$\begin{array}{l}\text { Piorou } \\
\text { muito }\end{array}$} & \multicolumn{2}{|c|}{$\begin{array}{l}\text { Piorou } \\
\text { pouco }\end{array}$} & \multicolumn{2}{|c|}{$\begin{array}{l}\text { Não houve } \\
\text { alteração }\end{array}$} & \multicolumn{2}{|c|}{$\begin{array}{l}\text { Melhorou } \\
\text { pouco }\end{array}$} & \multicolumn{2}{|c|}{$\begin{array}{l}\text { Melhorou } \\
\text { muito }\end{array}$} & \multicolumn{2}{|c|}{$\begin{array}{ll}\text { Qtd } & \text { de } \\
\text { Respostas } \\
\text { válidas }\end{array}$} & \multicolumn{2}{|c|}{$\begin{array}{l}\text { Sem } \\
\text { Resposta }\end{array}$} \\
\hline & Qtd & $\%$ & Qtd & $\%$ & Qtd & $\%$ & Qtd & $\%$ & Qtd & $\%$ & Qtd & $\%$ & Qtd & $\%$ \\
\hline $\begin{array}{l}\text { Transporte } \\
\text { Público }\end{array}$ & 0 & $0 \%$ & 0 & $0 \%$ & 3 & $5 \%$ & 9 & $14 \%$ & 51 & $81 \%$ & 63 & $100 \%$ & 0 & $0 \%$ \\
\hline $\begin{array}{l}\text { Drenagem de } \\
\text { águas } \\
\text { pluviais }\end{array}$ & 1 & $2 \%$ & 4 & $6 \%$ & 7 & $11 \%$ & 8 & $13 \%$ & 43 & $68 \%$ & 63 & $100 \%$ & 0 & $0 \%$ \\
\hline $\begin{array}{l}\text { Coleta de } \\
\text { Lixo }\end{array}$ & 1 & $2 \%$ & 0 & $0 \%$ & 17 & $27 \%$ & 9 & $14 \%$ & 36 & $57 \%$ & 63 & $100 \%$ & 0 & $0 \%$ \\
\hline $\begin{array}{l}\text { Distribuição } \\
\text { de água }\end{array}$ & 1 & $2 \%$ & 0 & $0 \%$ & 5 & $8 \%$ & 29 & $46 \%$ & 28 & $44 \%$ & 63 & $100 \%$ & 0 & $0 \%$ \\
\hline $\begin{array}{l}\text { Coleta } \\
\text { esgoto }\end{array}$ & 3 & $5 \%$ & 4 & $6 \%$ & 37 & $59 \%$ & 10 & $16 \%$ & 9 & $14 \%$ & 63 & $100 \%$ & 0 & $0 \%$ \\
\hline $\begin{array}{l}\text { Iluminação } \\
\text { Pública }\end{array}$ & 1 & $2 \%$ & 2 & $3 \%$ & 47 & $75 \%$ & 4 & $6 \%$ & 9 & $14 \%$ & 63 & $100 \%$ & 0 & $0 \%$ \\
\hline Educação & 0 & $0 \%$ & 0 & $0 \%$ & 31 & $72 \%$ & 8 & $19 \%$ & 4 & $9 \%$ & 43 & $68 \%$ & 20 & $32 \%$ \\
\hline Saúde & 0 & $0 \%$ & 0 & $0 \%$ & 47 & $92 \%$ & 3 & $6 \%$ & 1 & $2 \%$ & 51 & $81 \%$ & 12 & $19 \%$ \\
\hline$\%$ global & 7 & $1 \%$ & 10 & $2 \%$ & 194 & $41 \%$ & 80 & $17 \%$ & 181 & $38 \%$ & 472 & & & \\
\hline $\begin{array}{l}\text { Avaliação } \\
\text { geral }\end{array}$ & 0 & $0 \%$ & 0 & $0 \%$ & 2 & $3 \%$ & 14 & $22 \%$ & 47 & $75 \%$ & 63 & & 0 & $0 \%$ \\
\hline $\begin{array}{l}\text { Estrato I } \\
\text { (Transporte, } \\
\text { drenagem, } \\
\text { coleta de lixo } \\
\text { e distribuição } \\
\text { de água) }\end{array}$ & 3 & $2 \%$ & 4 & $2 \%$ & 32 & $17 \%$ & 55 & $29 \%$ & 158 & $84 \%$ & 189 & & & \\
\hline $\begin{array}{ll}\text { Estrato } & \text { II } \\
\text { (Coleta } & \text { de } \\
\text { esgoto) } & \end{array}$ & 3 & $5 \%$ & 4 & $6 \%$ & 37 & $59 \%$ & 10 & $16 \%$ & 9 & $14 \%$ & 63 & & & \\
\hline $\begin{array}{l}\text { Estrato III } \\
\text { (iluminação, } \\
\text { educação e } \\
\text { saúde) }\end{array}$ & 1 & $1 \%$ & 2 & $1 \%$ & 125 & $80 \%$ & 15 & $10 \%$ & 14 & $9 \%$ & 157 & & & \\
\hline
\end{tabular}

Nota. Fonte: Dados coletados nos 63 domicílios pesquisados por meio do questionário estruturado do levantamento survey.

Analisando os dados, percebe-se que emergem três padrões de respostas. O primeiro padrão (Estrato I) é composto pelos serviços de transporte público, drenagem de águas pluviais, coleta de lixo e distribuição de água. Estes serviços, em termos da percepção de qualidade pelos cidadãos, caracterizam-se por uma expressiva melhora na qualidade. O segundo padrão (Estrato II) é composto pelo serviço de coleta de esgoto. Este serviço, em termos da percepção de qualidade, caracteriza-se por uma divisão na percepção dos cidadãos: alguns consideram que o serviço melhorou (30\% dos respondentes), e a maioria considera que não houve alteração na qualidade do serviço prestado (59\% dos respondentes). O terceiro padrão (Estrato III) é composto pelos serviços de iluminação pública, educação e saúde. Estes serviços, em termos da percepção de qualidade, caracterizam-se pelo predomínio de respondentes que consideram não ter havido alteração (75\% para iluminação pública, $72 \%$ para educação e $92 \%$ para saúde).

\section{Resultados}

Estrato I: Serviços com percepções de melhorias na qualidade

Conforme apresentado na seção anterior, este estrato é formado pelos serviços de transporte público, drenagem de águas pluviais, coleta de lixo e distribuição de água.

No sentido de compreender melhor os aspectos que contribuíram para a percepção de qualidade mais positiva com estes serviços, as entrevistas de profundidade trouxeram elementos de natureza mais detalhada sobre os níveis de satisfação e explicativa sobre os porquês desses níveis (Altman, 2001, Cardoso \& Cardoso, 2011, Scott \& Vitartas, 2008, Van Ryzin, 2004).

Serviço de distribuição de água

Em relação ao posicionamento da população sobre as mudanças proporcionadas com a implantação do sistema de distribuição de água, mesmo com $90 \%$ da população afirmando que houve melhora no serviço ( $46 \%$ afirmando que melhorou pouco e $44 \%$ afirmando que melhorou muito, contra $2 \%$ que afirmam que piorou muito e $8 \%$ que afirmam que não houve alteração), as entrevistas de profundidade trouxeram elementos que relatam alguns problemas que surgiram com a instalação do novo sistema de distribuição de água. Por exemplo, um entrevistado relatou que ainda existem resquícios do mercado paralelo de venda de água tão 
comum na situação anterior à intervenção analisada: "hoje tem muita gente vendendo água por aí. Uma coisa que eu não concordo. Uma pessoa ter que comprar por $R \$ 15$ dois latões de água”.

Segundo ele, o fornecimento de água apresenta intermitência e qualidade insuficiente até mesmo em relação a uma avaliação básica de aspecto (cheiro e coloração). Esse entrevistado afirma que, frequentemente, há situações em que o sistema de distribuição de água fica por dias sem abastecer a comunidade. Outro cidadão entrevistado corrobora esta percepção e cita a intermitência do abastecimento: "a rede já está instalada, porém não está chegando água ainda com a mudança. Falha muito. Não sei se por causa da época, mas tive que comprar um carro pipa anteontem por causa da falta de água. Não está chegando essa água com precisão, ainda falha muito". Sobre a qualidade insuficiente, um cidadão entrevistado comentou que "quando ela está forte ela vem limpa, mas quando a pessoa tem que puxar ela vem suja, podre, amarela. Coisa que antigamente aqui não tinha isso".

A partir dos trechos apresentados e confrontados com 0 resultado do levantamento survey, infere-se que os cidadãos respondentes defendem que a situação pós-intervenção em relação ao acesso de água é superior à situação pré-intervenção, em termos gerais, porque antes sequer havia o sistema de distribuição de água, - que causava a situação na qual os moradores necessitavam realizar longos percursos atrás deste recurso. Contudo, a análise sobre a prestação do serviço feita de forma mais detalhada nas entrevistas sugere que a distribuição ainda carece de um desempenho mais estável e confiável porque muitos demonstraram níveis altos de insatisfação.

Serviço de drenagem de águas pluviais

Em relação ao posicionamento da população sobre as mudanças proporcionadas com a implantação do sistema de drenagem de águas pluviais, mesmo com $81 \%$ da população afirmando que houve melhora no serviço (13\% afirmando que melhorou pouco e $68 \%$ afirmando que melhorou muito, contra $8 \%$ afirmando que piorou e $11 \%$ que não houve alteração), as entrevistas de profundidade trouxeram mais detalhes que permitem compreender essa situação.

Um cidadão entrevistado declarou que "antigamente isso aqui era tudo lama". Essa descrição foi confirmada por dois outros cidadãos. O primeiro afirma: "era horrível o bairro, quando chovia era muita lama. Problema de enchente nas ruas. Chovia e enchia a Rua Principal. A gente tinha que sair descalço até a Nova Holanda, lavar os pés e calçar o calçado para ir trabalhar". O segundo complementa afirmando que "aqui, em todas as ruas, o pessoal andava com sacolas nos pés porque aqui era muita lama. Usava as botinas e quando chegava no Brizolão, guardava e ia trabalhar; Era uma área muito precária".

Sobre esse serviço, constata-se que, uma vez que sua oferta é, naturalmente, a mais condicionada pela simples instalação de infraestrutura física, com pouca ou nenhuma necessidade de operação no dia a dia, a percepção dos moradores sugere que infraestrutura instalada, de fato, gerou impactos positivos em relação à situação degradante existente antes da intervenção.

\section{Serviço de coleta de lixo}

Em relação ao posicionamento da população sobre as mudanças proporcionadas no serviço de coleta de lixo, mesmo com $71 \%$ da população afirmando que houve melhora no serviço ( $14 \%$ afirmando que melhorou pouco e $57 \%$ afirmando que melhorou muito, contra $2 \%$ afirmando que piorou e $27 \%$ que não houve alteração), as entrevistas de profundidade trouxeram mais detalhes que permitem compreender essa situação.

Apenas um cidadão respondente demonstrou insatisfação com o serviço: "continua a mesma coisa, na minha rua não tem coleta. Antes a justificativa era porque era uma rua sem saída, hoje é uma rua com saída e não te coleta. A gente joga na esquina da Principal, pois lá passa. Acaba se tornando um lixão ali". Em contraponto, os demais cidadãos respondentes defenderam que o serviço melhorou, principalmente devido à facilitação do acesso dos veículos coletores pela pavimentação do sistema viário feita pela intervenção.

Este serviço já era prestado pela municipalidade antes da intervenção. Dessa forma infere-se que a percepção positiva mensurada foi causada pela melhoria na pavimentação, que possibilitou que a prestação desse serviço ocorresse com mais eficácia, e não por mudanças específicas na lógica pela qual esse serviço é ofertado.

Serviço de transporte público

Em relação ao posicionamento da população sobre as mudanças proporcionadas no serviço de transporte público ofertado na localidade, $95 \%$ da população afirmou que houve melhora no serviço (14\% afirmando que melhorou pouco e $81 \%$ afirmando que melhorou muito, contra $5 \%$ afirmando que não houve alteração), as entrevistas de profundidade trouxeram mais detalhes que permitem compreender essa situação.

De forma quase unânime, os cidadãos respondentes corroboraram o resultado mensurado pelo levantamento survey. Por exemplo, um cidadão entrevistado relatou que: "os ônibus hoje passam nas ruas todas aqui, entendeu? Isso antes não era possível. Tenho usado o transporte. Porque, antigamente o transporte parava só na Rua Nove na Nova Holanda e a gente tinha que sair daqui e ir até lá. Hoje o ônibus passa praticamente na porta. Isso melhorou muito".

Este serviço não era prestado na localidade devido às péssimas condições das suas ruas, com inúmeros buracos e sem pavimentação. A falta de drenagem também contribuía negativamente, acarretando situações de inundação que 
impossibilitavam 0 acesso aos veículos utilizados pela concessionária do serviço de transporte municipal. Dessa forma, infere-se que a intervenção possibilitou o início da prestação do serviço e com isso gerou a percepção majoritariamente positiva nos cidadãos.

Estrato II: Serviços para os quais houve percepções de pequena melhoria ou nenhuma alteração

Este estrato é formado apenas pelo serviço de coleta de esgoto. Em relação ao posicionamento da população sobre as mudanças proporcionadas com a implantação desse sistema, $30 \%$ da população afirmaram que o serviço melhorou (16\% afirmando que melhorou pouco e $14 \%$ afirmando que melhorou muito), $11 \%$ afirmaram que piorou ( $5 \%$ relataram piorou muito e $6 \%$ que piorou pouco) e $8 \%$ que afirmaram que não houve alteração.

Buscou-se compreender melhor esta divisão na percepção dos cidadãos respondentes por meio das entrevistas de profundidade. Em termos do serviço de coleta de esgoto prévio à intervenção, entrevistas com os cidadãos descrevem que não havia qualquer sistema de coleta de esgoto disponível. Um cidadão entrevistado declarou: "aqui é fossa sumidouro, mas que nunca funcionou porque a área é alagada. Está lá, no meu eu fiz: fossa, filtro e sumidouro. Sempre procurei andar de acordo com a legislação".

A intervenção realizada tinha o objetivo de construir uma rede coletora no terço beneficiado pelas intervenções do PAC na comunidade de Nova Esperança e interligá-la a uma estação de tratamento de esgotos, que estava sendo construída próxima a uma comunidade vizinha. Entretanto, a obra da estação de tratamento de esgotos atrasou. Em suas entrevistas, profissionais da equipe técnica relataram que a rede coletora implantada na localidade de Nova Esperança necessitava de uma interligação com a estação de tratamento para que o sistema de coleta de esgoto pudesse de fato operar. A obra do sistema de coleta de esgoto em Nova Esperança foi concluída e entregue para a população, entretanto, sem que a obra da estação de tratamento fosse concluída.

No Brasil, a responsabilidade de interligação da rede de saneamento básico pública com cada residência é do morador. 0 passo lógico seguinte à entrega oficial da rede coletora no terço beneficiado do aglomerado subnormal era a interligação de cada residência a esta rede. Entretanto, como a estação de tratamento não estava concluída, foi solicitado a cada morador que esperasse pela conclusão da obra da estação para realizar a conexão com a rede coletora. O survey e as entrevistas confirmaram que nem todos os moradores esperaram a sinalização por parte da prefeitura: "Esgoto não tinha. Era jogado nos terrenos. Geralmente, nem era fossa, era jogado direto. Agora eles fizeram a ligação de esgoto. Uma rua lá atrás tem uma manilha e uma máquina que puxa e joga para outro lugar".
Entretanto, apesar da conclusão da obra de infraestrutura local, foram percebidos muitos problemas relativos à operação do serviço de coleta de esgoto. Com a estação de tratamento não funcionando e a realização das conexões domiciliares, não havia destinação final do esgoto despejado.

Dentre os que afirmam que houve piora do serviço, as entrevistas em profundidade também apontam para o mesmo resultado. As entrevistas permitem sugerir que a insatisfação com a infraestrutura implantada esteja relacionada com os vazamentos na rede de coleta de esgoto. Um entrevistado afirmou que: "o que eles fizeram na rua está jogando para fora. A água de esgoto, você vai na maioria das ruas e você vê esgoto jogando para fora". Outro entrevistado corrobora essa afirmação e diz que "tem ruas que estão calçadas, mas assim quando chove os esgotos estão transbordando. Sobe para a rua. Choveu e transborda. Antes não tinha, cada um fazia seu buraco. Mas, transborda".

Em última análise, os resultados da pesquisa no tocante à construção de infraestrutura para coleta de esgotos sugerem que houve expressiva insatisfação com os resultados entregues. Considera-se que esta insatisfação está relacionada aos problemas na sincronização fina da finalização das duas obras interdependentes e da ineficácia da comunicação sobre o impedimento das ligações à rede coletora.

Estrato III: Serviços sem alteração na percepção de qualidade dos serviços

Este estrato é formado pelos serviços de iluminação, saúde e educação. A intervenção analisada não empregou investimentos diretos na infraestrutura relacionada a esses serviços. Entretanto, argumenta-se neste artigo que os serviços públicos não necessariamente são incrementados a partir de investimentos diretos em infraestrutura. Portanto, mesmo não tendo recursos para a parte infraestrutural relacionada aos serviços de iluminação pública, saúde e educação, parte-se do pressuposto que a intervenção analisada poderia proporcionar melhorias em ambos os serviços. Tal premissa se baseia na discussão levantada por Almeida e Tokeshi (2011), quando questionam a comum visão no Brasil de colocar a infraestrutura enquanto produtora direta de resultados. Eles propõem pensar na infraestrutura como meio para a implantação de sistemas de serviços que resolvam necessidades fundamentais do nosso dia a dia, como energia, comunicação, locomoção, logística, saneamento, saúde e educação (Almeida \& Tokeshi, 2011, p. 149). Durante toda a argumentação dos autores, há a proposição concreta de mudança de foco na discussão de planejamento de infraestrutura para a dimensão dos sistemas de serviço: "o principal da infraestrutura não é a obra em si, mas o serviço público prestado com base na obra" (Almeida \& Tokeshi, 2011, p. 150). 
Decidiu-se, assim, perguntar aos moradores sobre suas percepções acerca da qualidade de serviços locais essenciais sem relação direta com o investimento em infraestrutura.

Dessa forma, as entrevistas de profundidade também forneceram insumos para a compreensão dos aspectos relacionados ao fato dos cidadãos terem considerado que tais serviços não foram alterados com a intervenção.

Serviços de iluminação pública

Em relação ao posicionamento da população sobre as mudanças proporcionadas sobre o serviço de iluminação pública, $75 \%$ afirmam que não houve alteração, contra $20 \%$ da população que afirmaram que houve melhora no serviço ( $6 \%$ afirmando que melhorou pouco e $14 \%$ afirmando que melhorou muito, contra $3 \%$ que afirmam que piorou pouco e $2 \%$ que piorou muito).

Um cidadão respondente disse que após a intervenção houve uma regularização das ligações clandestinas de energia que, segundo ele, melhoraram o fornecimento do serviço. Outro cidadão também apresentou satisfação com o serviço, pois, segundo ele, a intervenção contribuiu para a redução da violência que existia na comunidade e acabou interferindo diretamente na condição do serviço. Isso porque era interessante para alguns que a comunidade estivesse mais escura em diversos pontos e, para isso, havia destruição constante de lâmpadas e transformadores.

Por outro lado, um cidadão apresentou postura mais negativa em relação a este serviço, afirmando que "hoje ainda está precário. Estou há 4 meses querendo uma instalação de luz para mim e está em estudo de rede. Para atender a demanda de alguém que necessite de uma energia mais forte, eles ainda não atendem. Tudo que necessite de mais força, eles estão protelando". Outro cidadão reclamou do serviço que estava sendo prestado após a intervenção: "eu pago a taxa e na minha rua a gente não tem iluminação pública. Minha rua é escura, em frente à minha casa é totalmente escuro".

Serviços de saúde pública

Em relação ao posicionamento da população sobre as mudanças proporcionadas sobre o serviço de saúde pública, $92 \%$ afirmam que não houve alteração, contra $8 \%$ da população que afirmaram que houve melhora no serviço ( $6 \%$ afirmando que melhorou pouco e $2 \%$ afirmando que melhorou muito).

Dois cidadãos respondentes defenderam que a Unidade de Pronto Atendimento (UPA) existente na Barra e o Posto da Nova Holanda (regiões adjacentes à localidade) atende bem a comunidade de Nova Esperança. Contrariamente, cinco cidadãos relataram precariedade no atendimento de saúde à comunidade. Sobre a situação atual, um cidadão entrevistado relata: "a gente não tem (serviço de saúde). Tem um postinho lá na Nova Holanda que atende Nova Holanda e Nova Esperança. Não dá conta. Muita gente não vai".
Outro cidadão, dentre esses que criticou a prestação de serviços de saúde, comentou que o serviço tinha maior oferta em passado recente: "tinha um posto de saúde que funcionava, ficava bem na divisa e por causa do tráfico acabou. Hoje tem um postinho provisório ali, mas as pessoas daqui saem para buscar tratamento fora nas UPAs e hospitais. Aqui dentro nós precisamos. Tem só um posto que atende, é provisório. Pegaram uma casa e estão dando atendimento, mas é precário". Outro beneficiário foi ainda mais enfático na crítica ao explicar a falta de assistência a um parente cadeirante em: "o serviço de saúde é o pior possível. Eu levei 2 anos e meio procurando o pessoal do posto para atender meu esposo. Não veio médico, nem fisioterapeuta (...) quando o postinho da rua 9 fechou, há uns três anos, perguntei no centro e eles disseram que o posto que ficou era o responsável. Fui lá e falei para eles que ele era cadeirante e que eu precisava de acompanhamento médico, mas nada aconteceu".

Serviços de educação pública

Em relação ao posicionamento da população sobre as mudanças proporcionadas sobre o serviço de educação pública, $72 \%$ afirmam que não houve alteração, contra $28 \%$ da população que afirmaram que houve melhora no serviço (19\% afirmando que melhorou pouco e $9 \%$ afirmando que melhorou muito).

Todos os cidadãos respondentes enfatizaram a disponibilidade de escolas na área ao redor de Nova Esperança, tanto na divisa com Nova Holanda, onde fica um colégio de gestão estadual (conhecido popularmente como Brizolão), quanto em bairros próximos como a Barra de Macaé, onde se localizam escolas municipais. É interessante salientar que não surgiram reclamações sobre a distância das unidades escolares, o que sugere que os cidadãos não percebem a variável tempo de deslocamento como crucial para a qualificação do serviço, como fazem para os serviços de saúde.

O comentário de um cidadão respondente faz referência à maior capacidade das escolas municipais em manter uma relação aluno por sala de aula mais adequada do que a escola estadual, única presente no bairro, em: "os colégios da prefeitura são totalmente diferentes do Brizolão. Acho que é porque tem muita gente estudando no Brizolão. A escola da prefeitura é bem melhor".

Tais relatos possibilitam inferir que a intervenção, de fato, se ateve às questões relacionadas diretamente à infraestrutura, não causando mudanças significativas em serviços já existentes, sejam os que apresentavam uma oferta satisfatória, sejam os que apresentavam oferta insatisfatória antes da intervenção.

\section{Considerações Finais}

Este artigo contribui para discussões acerca dos efeitos das intervenções urbanas realizadas no âmbito do Programa de Aceleração do Crescimento (PAC). Para isso, apresentou um estudo de caso no aglomerado subnormal Nova Esperança, no município de 
Macaé, estado do Rio de Janeiro. O artigo analisou a percepção de qualidade e os níveis de satisfação da população que residia no local modificado tanto antes quanto depois da intervenção, sobre os novos sistemas de infraestrutura urbana recebidos (unidades habitacionais, implantação de um sistema de distribuição de água, de um sistema de coleta de esgoto e de um sistema de drenagem de águas pluviais) e os serviços urbanos básicos (serviços de educação e serviços de saúde) prestados na localidade em análise.

Em termos de resultados, percebeu-se que 97\% das respostas no quesito avaliação geral da melhoria no bairro proporcionada pela intervenção foram positivas (75\% dos respondentes do levantamento survey responderam que o bairro melhorou muito e $22 \%$ que melhorou pouco, contra apenas 3\% que disseram que não houve alteração). Ou seja, demonstrou-se no geral que a população estava mais satisfeita em relação à situação anterior à intervenção.

Entretanto, analisando-se o percentual de respostas em cada ponto da escala, percebe-se uma diferença significativa em termos da avaliação: $41 \%$ das respostas foram "não houve alteração", e apenas $38 \%$ foram "melhorou muito" e $17 \%$ foram "melhorou pouco". Tais diferenças nos níveis de satisfação podem ser explicadas, em parte, pelas especificidades das percepções de qualidade coletadas serviço a serviço.

Analisando as razões para esta diferença quanto a avaliação geral e a avaliação serviço a serviço, 40 dos 63 respondentes forneceram explicações para sua avaliação geral. Dentre esses 40 respondentes, 68\% (27 respondentes) apontaram a resolução do problema da lama nas ruas da localidade como o principal benefício oriundo da intervenção. Curioso é observar que, apesar de a resolução do problema da lama, que tanto afligia a população local, ter sido de fato um grande ganho, a satisfação com os serviços públicos urbanos como um todo não foi alterada na mesma magnitude.

Infere-se que o fato de que a infraestrutura básica resolveu problemas como o lamaçal nas ruas, a eliminação da necessidade de grandes deslocamentos para acesso a água e a mitigação das enchentes ocasionada por chuvas fez com que a população reconhecesse o valor da intervenção e ficasse mais satisfeita. Esta parece ter sido a racionalidade que explica a avaliação geral ter sido majoritariamente positiva, sem que houvesse para essa avaliação geral forte influência da qualidade dos serviços habilitados pela intervenção. Nesse ponto, conclui-se que a percepção de qualidade não explica totalmente o nível de satisfação dos cidadãos, ou seja, há relação entre eles, mas outros fatores parecem influenciar o momento de satisfação apreendido. Conforme visto no modelo utilizado por Cardoso e Cardoso (2011), é possível que outros antecedentes tenham influenciado positivamente os níveis de satisfação, dentre os quais, a expectativa, haja vista o histórico de pouca ação do governo municipal naquela localidade.
Para continuarem avançando, as pesquisas devem buscar a construção de proposições conceituais e verificações empíricas que relacionem outras variáveis para explicar como os níveis de satisfação são influenciados. Contudo, é preciso fazer com que tais pesquisas retroalimentem 0 conhecimento sobre como as municipalidades brasileiras deveriam projetar serviços públicos urbanos geridos ou governados por elas em busca de mais impacto.

Em última análise, este artigo provê evidências de que as intervenções urbanas no âmbito do Programa de Aceleração do Crescimento replicam, de certa forma, o modus operandi com o qual os governos locais brasileiros têm tentado transformar territórios excluídos no processo de urbanização brasileiro nas últimas décadas. Continua-se enfatizando os volumes orçamentários aplicados nos aglomerados subnormais de forma pontual, sem que haja predomínio da atuação perene com serviços públicos de qualidade derivados dessas intervenções. Dessa forma permanece a tendência de que a população não tenha de fato mudanças transformadoras que assegurem sua qualidade de vida pósintervenção.

\section{Referências}

Abiko, A. E. \& Coelho, L. de O. (2009). Urbanização de favelas: procedimentos de gestão. Porto Alegre, ANTAC.

Almeida; B. e Tokeshi, H. (2011). Os gargalos de infraestrutura e a criação de um sistema moderno de serviços públicos. In: Giambiaggi, F. \& Porto, C., 2022: propostas para um Brasil melhor no ano do bicentenário. Rio de Janeiro: Elsevier, Campus.

Altman, S. (2001). Measuring Street Cleanliness: A Comparison of New York City's Scorecard and Results from a Citizen Survey. Public Administration Review, 68 (2), 295-303.

Andrews, R., Boyne, G. A., Law,J. \& Walker, R. (2005). External constraints on local service standards: the case of comprehensive performance assessment in English local government. Public Administration, 83(3), 639-656. doi: 10.1111/j.0033-3298.2005.00466.x.

Bailey, K. (1994). Typologies and Taxonomies: An Introduction to Classification Techniques. Quantitative applications in the social sciences series. London: Sage Publications.

Ball, R. e Beckett, A., (1991), "Performance evaluation in a Local Government: The case of a Social Work Department meals-on-wheels service" European Journal Of Operational Research, v. 51, pp. 35-41.

Bardin, L. (2008). Análise de conteúdo. Lisboa: Edições 70.

Bouckaert, G. \& Van Dooren, W. (2009). Performance measurement and management in public sectors organizations. In: Bovaird, T. e Löffler, E. Public Management and Governance. 2 ed. London: Routledge.

Boyne, G. A., Meier, K, O'Toole Jr L., \& Walker, R. (2006). Public Service Performance. Cambridge: Cambridge University Press.

Brito, F. A. \& Pinho, B. A. T. D. de. (2012). A dinâmica do processo de urbanização no Brasil, 1940-2010. Texto para discussão n 464. Belo Horizonte: UFMG/CEDEPLAR.

Cardoso, A. \& Cardoso, A. (2011). Qualidade e satisfação na administração local: avaliação da satisfação dos munícipes da Amave NUTIII/AVE. Revista de Administração Pública, 45(4), 1003-1030.

Fontanella, B. J. B., Luchesi B. M.; Saidel M. G. B., Ricas, J., Turato, E. R. \& Melo, D. G., (2011). Amostragem em pesquisas qualitativas: proposta de procedimentos para constatar saturação teórica. Caderno de Saúde Pública, Rio de Janeiro, 27(2).

Heinrich, C. J., (2010). Como avaliar o desempenho e a efetividade do setor público. In: Peters, G. e Pierre, J. Administração Pública: Coletânea. Brasília, DF: ENAP.

IBGE. (2001). Censo Demográfico 2000. Recuperado de http://www.ibge.gov.br/home/estatistica/populacao/censo2000/.

IBGE. (2011). Censo Demográfico 2010. Recuperado de 
http://www.ibge.gov.br/home/estatistica/populacao/censo2010/.

IBGE (2016). IBGE Censo 2010: aglomerados subnormais. Recuperado de http://www.censo2010.ibge.gov.br/agsn/.

IBGE (2016). IBGE Cidades@. Recuperado de http://cidades.ibge.gov.br/.

Johnson, B.; Onwuegbuzie, A. \& Turner, L. (2007). Toward a definition of mixed methods research. Journal of Mixed Methods Research, 1(2), 112-133. doi: $10.1177 / 1558689806298224$.

Lago, L. C. do \& Ribeiro, L. C. Q. (2001). A divisão favela-bairro no espaço social do Rio de

Janeiro, in L. C. Q. Ribeiro e L. Bógus (org.), Cadernos Metrópole, 5, 37-59, 2001.

Leitão, K. O. (2009). A dimensão territorial do Programa de Aceleração do Crescimento: um estudo a partir do PAC no Estado do Pará e o lugar que ele reserva à Amazônia no desenvolvimento do país. Tese de Doutorado. São Paulo: Universidade de São Paulo.

Macaé (2010). Plano Local de Habitação de Interesse Social. Macaé: Prefeitura Municipal de Macaé.

Macaé (2012). Anuário Macaé 2012. Prefeitura Municipal de Macaé.

Macaé, (2016). Portal da Transparência. Recuperado de http://www.macae.rj.gov.br/conteudo/leitura/titulo/royalties.

Maricato, E. T. M.. (2009). Fighting for Just Cities in capitalism's periphery. In Peter Marcuse et al. (ed.). Searching for the just city : debates in urban theory and practice. New York: Routledge, 91-102.

Miguel, P.A. C. \& Sousa, R. (2012). O método do estudo de caso na engenharia de produção". In: Miguel, P. A. C.. Metodologia de pesquisa em engenharia e produção e gestão de operações. 2 ed, São Paulo: Campus, 131-148.

Ministério Da Fazenda (2013). Economia brasileira em perspectiva, março de 2013. Brasília

Murray, G. (2009). Towards a common understanding of the differences between purchasing, procurement and commissioning in the UK public sector. Journal of Purchasing and Supply Management, 15(3), 198-202.

Moran-Ellis, J.; Alexander, V.; Cronin, A. Dickinson, M., Fielding, J.; Sleney, J. \&; Thomas, H. (2006). Triangulation and integration: processes, claims and implications. Qualitative Research, 6(1), 45-59. doi: 10.1177/1468794106058870.

Muxica, L. S. M. (2011). La favela como espacio de exclusión social en la ciudad de Rio de Janeiro. EURE (Santiago), 37(110), 117-132. doi: 10.4067/S0250-71612011000100005.

Oliveira, B. C. D. S. (2011). Políticas Públicas e Participação Popular Na Implementação Do PAC Social No Complexo Do Alemão, Rj. Dissertação de Mestrado. Rio de Janeiro. Universidade Federal Fluminense.

PNUD (2013). Atlas do Desenvolvimento Humano no Brasil 2013: Metodologia. [On-line] <http://www.pnud.org.br/arquivos/fs3-metodologia.pdf.>. [23 de abril de 2014].

Sano, H. \& Filho, M. J. F. (2013). As técnicas de avaliação da eficiência, eficácia e efetividade na gestão pública e sua relevância para o desenvolvimento social e das ações públicas. Desenvolvimento em Questão, 11 (22), 35-61.

Scott, D. \& Vitartas, P. (2008). The role of involvement and attachment in satisfaction with local government services. International Journal of Public Sector Management, 21(1), 45 - 57.

Spiegel, M. (2009). Estatística. 3. ed. São Paulo: Pearson Makron Books.

Telles, V. da S, (2010). As cidades nas fronteiras do legal e ilegal. Belo Horizonte: Argvmentvm.

Van Ryzin, G. G. (2004). Expectations, performance, and citizen satisfaction with urban services. Journal of Policy Analysis and Management, 23(3), 433448. doi: 10.1002/pam.20020.

Yin, R. (2014). Case study research: design and methods. Applied Socia Research Methods

Series, 5 ed. London: Sage Publications. 